\title{
A CISÃO DO PRESENTE: A EXPERIÊNCIA ENTRE PALAVRAS E IMAGENS
}

\section{THE SPLIT OF THE PRESENT: THE EXPERIENCE BETWEEN WORDS AND IMAGES}

Hernán Ulm

RESUMO: Se o problema central para o pensamento, segundo Foucault, é pensar aquilo que somos, o presente trabalho quer compreender as condicóes da experiência contemporânea, tomando como chave de leitura, as diferenças entre palavras e imagens. Segundo se propóe, tais diferenças, decorrentes das materialidades e das tecnologias, que sâo próprias às palavras e às imagens, apresentam duas modalidades do tempo, que náo podem concordar: do lado da linguagem, o tempo como História, do lado das imagens, o tempo como Memória. Pensar as qualidades desses tempos só resulta possível a partir da literatura e do cinema, tanto em um trabalho com e contra as palavras, quanto com e contra as imagens, respetivamente. Há, no presente, alguma coisa de irreconciliável. Esse irreconciliável năo é um acaso, senáo a condiçăo mesma aberta pela cisâo dos tempos como marca determinantes disso que somos.

Palavras-chave: cisăo; experiência; Literatura; cinema; incomunidade.

ABSTRACT: If the central problem for thought (Foucault) is to think of what we are, this paper aims to understand the conditions of contemporary experience, taking as a reading-key the differences between words and images. According to what is proposed, such differences present, arising from materialities and technologies that are proper to words and images, two modalities of time that cannot agree: on the side of language, time as History, on the side of images time as Memory. The exercise of thinking on the qualities of these times is only possible if it is from Literature and cinema perspectives, both egagged with and against words as with and against images respectively. Thus, there is at the present time something irreconcilable. And this is not a matter of chance, but the very condition generated/opened by the split of the times as a determinant mark of what we are.

Keywords: split; experience; Literature; cinema; incommunity.

Diretor do IICA - Instituto de Investigaciones en Cultura y Arte e Professor de Estética da UNSA Universidad Nacional de Salta. Doutor em Literatura comparada (UFF). 


\title{
A cisão do presente: a experiência entre palavras e imagens
}

\begin{abstract}
Recém-chegado e ignorando totalmente as línguas do Levante, Marco polo só podia se exprimir extraindo objetos de suas malas: tambores, peixes salgados, colares de dentes de facoqueros (sic) e, indicando-os com gestos, saltos, gritos de maravilha ou de horror, ou imitando o latido do chacal e o pio do cocho [...] Mas o que Kublai considerava valioso em todos os fatos e notícias referidas por seu inarticulado informante era o espaço que restava em torno deles, um vazio náo preenchido por palavras [...] Com o passar do tempo, nas narrativas de Marco, as palavras foram substituindo os objetos e os gestos: no início, exclamaçóes, nomes isolados, verbos secos; depois, torneios de palavras, discursos ramificados e frondosos, metáforas e imagens [...] E, enquanto o vocabulário das coisas renovava-se com o mostruário das mercadorias, o repertório dos comentários mudos tendia a se fechar e se estabelecer. 0 prazer de ambos em recorrer a eles também diminuía; em suas conversas, permaneciam a maior parte do tempo calados e imóveis (CALVINO, 1990, p. 42-43).
\end{abstract}

\section{Introdução: 0 umbral do presente}

Desde a segunda metade do século XX, parece claro que já năo podemos confiar a realidade do ser e do pensar à linguagem: ela năo mais define para nós o sentido de todo o que podemos pensar. $E$ isso porque, na saída da virada linguística, que atravessou grande parte do século passado, o pensamento contemporâneo tem encontrado nas imagens outras economias, outras lógicas e outras determinaçōes năo linguísticas de configuraçấo do sentido. E se, durante um tempo considerável, as imagens foram pensadas como um tipo especial de língua, aos poucos essas análises se mostraram insatisfatórias. As imagens eram concebidas como portadoras de uma força, como configuradoras de uma experiência que, aquém ou além da linguagem, passava irreconhecível para ela.

Por isso, nâo se trata aqui das relaçôes que "em geral" mantém palavras e imagens, senăo do modo específico em que se coloca essa relaçăo hoje (nesse sentido, essa relaçăo, tal e como quero falar neste artigo, nâo diz respeito às relaçôes que poderiam ser pensadas na perspectiva antiga do ídolo ou do ícone ou na perspectiva moderna da representaçâo e suas correspondentes filosofias da linguagem). No que me importa, há uma especificidade da relaçấo palavras e imagens a partir de um duplo acontecimento determinante, para pensar uma genealogia de nosso presente (quer dizer, para tentar compreender o modo pelo qual chegamos a ser "isso que somos" e a "atualidade" disso que somos, como sustentaria Deleuze na sua interpretaçấo de Foucault): a emergência da produtividade técnica das imagens, de um lado e o pensamento vitalista que considera a imagem como uma efetuaçăo da vida (Bergson, Warburg ), do outro, configuram o umbral a partir do qual nosso presente pode ser compreendido.

Neste sentido trata-se, também, de uma mutaçăo na estrutura mesma da imagem (do modo como a construímos - e do como ela nos constrói; do modo em que a pensamos - e ela nos pensa; e do modo como agimos diante delas - e do modo como sofremos suas açôes). Do lado técnico, elas aparecem produzidas sob as condiçōes do afastamento da mâo humana, da automatizaçăo e da proliferaçăo serial da ordem do visível. Do lado 
vitalista, as imagens săo uma condensaçâo de energias configuradoras do sentido que nelas encontra uma "vida póstuma" - Nachlebem - (Warburg) ou a matéria mesma do devir do mundo, como movimento e duraçáo (Bergson).

Para além das diferenças entre ambas dimensôes do acontecimento, que coloco no umbral de nossa atualidade, tanto do lado da emergência técnica como da filosofia da vida, as imagens năo sâo nem a reproduçâo ou o duplo do mundo, nem a representaçấo da consciência, nem a projeçấo da vida interior do espírito e, nem sequer, o resultado de expressâo da faculdade da imaginaçấo como exaltaçâo da produtividade humana. Embora náo seja o objeto deste artigo (uma análise precisa dos desdobramentos técnicos e vitalistas do pensamento em/das imagens exigiria um desenvolvimento que excede os limites da reflexăo que ora fazemos). Pensar nosso presente é levar em conta que a questăo das imagens e de suas relaçôes com a linguagem estăo, elas mesmas, atravessadas pelas questôes técnicas e vitalistas de produçăo de sentido.

\section{A questão do presente como cisão}

Nossa experiência do presente se encontra atravessada por uma dualidade, por uma ambiguidade pela qual, de um lado, continuamos sendo obrigados a falar (de nós, dos outros, do mundo, das coisas, de nossos sonhos e de nossos desejos mais íntimos num murmúrio incessante e de contínuo atordoamento); e, do outro, somos forçados a produzir imagens (de nós, dos outros, do mundo, das coisas, de nossos sonhos e de nossos desejos mais íntimos numa projeçăo perpétua de luzes que nos cegam constantemente). Aquilo que somos (para falar à maneira de Foucault: aquilo que podemos dizer, aquilo que podemos fazer, o modo de nos reconhecermos a nós mesmos no interior dos dispositivos de saber-poder) encontra-se cindido entre duas modalidades bem diferenciadas: uma pela qual somos feitos por palavras, outra pela qual somos feitos por imagens.

Nessa distância entre palavras e imagens acontece nosso presente. Decorre disso uma espécie de esquizofrenia que náo cessa de se aprofundar. Constituídos no meio de uma dobra (a dobra pela qual as imagens e as palavras disputam o horizonte do verdadeiro e do falso, a dobra pela qual acreditamos ora nas palavras, ora nas imagens), năo conseguimos nos equilibrar entre esses dois mundos que se abrem no interior de nós mesmos. Somos lançados pelas palavras contra as imagens e voltamos para as primeiras sem poder nos recolher na experiência das segundas. Há, no fundo, uma experiência dupla, que temos de percorrer incessantemente, tentando estabelecer os vínculos (im)possíveis entre essas bordas que se afastam. Essa năo-adequaçăo das regras da língua e às regras do Olhar, esse movimento pelo qual somos sussurrados nas palavras e exibidos pelas imagens, definem a condiçấo do que somos.

\section{0 irreconciliável}

Desse modo, nosso presente se apresenta como uma configuraçâo estranha, curiosa (embora, como sustentava Borges, todo presente se apresenta estranho e curioso para aqueles que habitam nele). Nele as palavras e as imagens se afastam, muito embora uma tensăo as mantenha juntas. A questăo se diferencia de outros modos de pensar as 
relaçōes entre imagens e palavras. No final das contas, tais relaçóes foram objeto de longas consideraçôes no pensamento Ocidental.

Tanto na tradiçăo grega como na tradiçăo cristâ, as afinidades e dissimetrias entre palavras e imagens foram objeto de preocupaçăo epistemológica e de debate teológico. Na modernidade, disputando-se o território da verdade, da fé, da moral ou da política, palavras e imagens organizam também o estatuto das representaçôes do Sujeito. Hoje, porém, as questóes que se disputam entre palavras e imagens atingem outros níveis de complexidade. As palavras náo explicam as imagens, que por sua vez, năo ilustram as palavras. Nem sobredeterminaçăo nem subordinaçăo. Abre-se entre elas, entâo, uma cisăo (uma "năo-relaçấo", parafraseando a Blanchot ) que as mantém juntas e que exige que as pensemos na sua "năo-complementaridade".

Nesse sentido, a questăo năo se apresenta como uma opçăo excludente que permitiria escolher entre as imagens ou as palavras (como se pudéssemos, por um esforço de nosso espírito, nos conformar com umas sem prestar atençăo às outras), senăo como a exigência por pensar juntas (nas junçôes que se disputam) as imagens e as palavras e o que entre elas tem se aberto como condiçâo de nossa experiência (nesse sentido náo há virada "icônica": năo se trata de afirmar que as imagens têm ocupado o lugar das palavras, senáo que as imagens têm aberto outro lugar para o pensamento, diferente daquele das palavras, que por sua vez, persistem com sua lógica própria).

Talvez essa seja a questăo mais perturbadora para a compreensăo "do que somos": o fato de que o pensamento possui duas lógicas incomparáveis, duas economias sem equivalência entre si e que, no entanto, compartilham o movimento do pensar. Nesse sentido, a língua năo deixa de existir no interior do regime de imagens tanto como as imagens permanecem no regime da língua, estabelecendo no interior de cada uma, incompatibilidades e fricçôes. Como sustenta Michel de Certeau (2011), a passagem de uma experiência da cultura para outra exige pensar as emergências, as desapariçōes e os deslocamentos de práticas e de objetos tanto como sua re-localizaçấo no novo modelo empírico.

Nesse sentido podemos dizer que aquilo que somos tem que ser compreendido na tensâo entre um "devir legível das imagens" e "um devir visível da linguagem": como podemos constatar desde o concretismo até os filmes de Godard, passando pelas experiências vanguardistas do início do século XX. A linguagem, descobrindo sua qualidade visual, deixa de lado sua funçâo de significaçăo para exigir, como se fosse uma imagem, ser também olhada. Assim como as imagens, se deslocando para o campo da linguagem, deixam de se exibir apenas como experiência visual e exigem ser lidas. Porém, nesses devires o que aparece sâo os limites que esses regimes nâo permitem ultrapassar: quando a imagem vira língua ou quando a palavra vira imagem se modifica, também, o estatuto de sua compreensáo. Nossa condiçăo de possibilidade é a abertura pela qual palavras e imagens expressam a distância que moramos sem encontrar nunca o local certo onde nos abrigar. Uma distância na qual umas e outras năo se deixam reconhecer.

De certo modo, toda a questáo parece muito simples: temos descoberto que as imagens năo săo palavras. Porém, em que consiste exatamente a diferença entre palavras 
e imagens? Qual é sua especificidade? Como essa diferença resulta decisiva para podermos pensar no interior do presente no qual somos? E, finalmente, como pensar essa diferença.

\title{
A condição em questão. literatura e cinema: transgressões e materialidades do sentido
}

\begin{abstract}
L'esthétique souffre d'une dualité déchirante. Elle désigne d'une part la théorie de la sensibilité comme forme de l'expérience possible; d'autre part la théorie de l'art comme réflexion de l'expérience réelle. Pour que les deux sens se rejoignent, il faut que les conditions de l'expérience en général deviennent elles-mêmes conditions de l'expérience réelle; l'œuvre d'art, de son côté, apparaît alors réellement comme expérimentation. ${ }^{2}$ (DELEUZE, 1969, p. 300)
\end{abstract}

Sempre que tentamos pensar as condiçôes que configuram o horizonte de nosso presente, se revela um paradoxo: de que modo pensar essas condiçóes nos mantendo no interior delas? Como permanecer na imanência do que essas condiçóes determinam e, ao mesmo tempo, acompanhar o movimento do que nelas se configura? Enfim, como fazer uma análise de nosso presente sem nos afastarmos imaginária ou utópica ou idealisticamente dele?

O fio condutor das tentativas de resposta a estas questóes é oferecido por uma análise dos limites estéticos de nossa experiência. Fazer uma experiência do mundo é se conformar aos limites consolidados do sensível (como estruturaçáo do espaço e do tempo). Porém, eles náo săo universais nem estăo prefigurados ou estruturados por uma consciência "geral" (qual espaço? qual tempo?). Pelo contrário, esses limites (e os modos de nos constituir como "consciência" no interior deles) săo históricos e dependem, cada vez, de modos precisos de agenciamento de nossa sensibilidade.

Deste modo, o que chamamos de "mundo comum" é apenas o gesto repetido, que tem como efeito a produçăo de uma sensibilidade feita cotidiana no interior desses agenciamentos (cada agenciamento produz um tipo de espaço e tempo que lhe sâo próprios). Por sua vez, sustentamos uma definiçâo (que tem uma dívida óbvia com o pensamento de Deleuze (ANO)) segundo a qual as artes sâo o trabalho do pensamento interrompendo os fluxos cotidianos da sensibilidade. Interromper nâo quer dizer ir para além desses fluxos senăo, melhor, afirmá-los e desviá-los, levá-los para outro lugar, detê-los e configurá-los, colocá-los em suspenso (dentre outras possibilidades). Por essa atividade de interrupçâo, as artes, podem, ao mesmo tempo, exibir as condiçóes do "mundo comum" produzido pelo agenciamento do presente e mostrar outros modos do "real", partindo do que o presente oferece: interromper é um modo de transformar uma experiência em uma "experimentaçăo" do sensível. Enfim, interromper é nos manter no interior dos limites do presente, extraindo desses limites as fugas que permitem sair dele.

A estética sofre de uma dualidade lancinante. Ela designa de um lado a teoria da sensibilidade como forma da experiência possível; por outro lado, a teoria da arte como reflexáo da experiência real. Para que os dois sentidos se reúnam, é necessário que as condiçôes da experiência em geral devenham, elas mesmas, das condiçóes da experiência real; a obra de arte, por sua vez, aparece entáo realmente como experimentaçâo. 
Assim, um índice para percorrer os limites de nossa experiência, como afastamento e diferença entre imagens e palavras, fica constituído pelo que, de modo muito esquemático e muito clássico, tem se chamado o problema da "adaptaçăo" entre literatura e cinema (pensados eles como interrupçóes da linguagem e da produçâo de imagens cotidianas, respectivamente). Logo no início, é possível perceber que as palavras da literatura năo se adaptam às imagens do cinema e que as imagens cinematográficas năo se adaptam às palavras literárias. Alguma coisa de insatisfatório (um excesso, uma falta) permanece nessa tentativa de se passar o legível para o visível ou este para aquele.

Poderíamos pensar que o problema é somente um acento de caráter "hermenêutico": palavras e imagens sendo apenas modalidades de um sentido único, que se interpreta segundo as regras da boa enunciaçâo ou as regras da boa visibilidade. Seria suficiente, entăo, refinar as regras da interpretaçăo para que entre palavras e imagens encontremos um eixo comum, um sentido único, se desdobrando como leitura ou como visâo. cinema e literatura poderiam se articular e serem analisados conforme princípios homólogos.

Porém, as diferenças entre palavras e imagens que aparecem entre literatura e cinema săo de outra ordem e dizem respeito às materialidades de expressăo. Como sustenta Deleuze, as materialidades náo săo neutras nem puras e o sentido que nelas se expressa năo é alguma coisa que apenas viria a se encarnar nelas. Pelo contrário, as materialidades săo elas mesmas expressivas de um sentido que lhes pertence (e só a elas pertencem). Assim a diferença entre literatura e cinema obriga a pensar nas materialidades próprias de cada prática, e ao que essas materialidades expressam cada uma por seu lado: năo apenas sutis modificaçōes de um sentido único, senáo a produçâo de um tempo e de um espaço (como condiçôes do sensível), que a outra năo pode compreender. Que sentido seria possível na condiçấo espaço temporal da materialidade das palavras e da materialidade que exigem as imagens?

No mesmo intuito, Vilém Flusser (1985) tem mostrado que as tecnologias comunicativas produzem cada vez, modulaçōes da sensibilidade segundo a qual se produzem descontinuidades nas formas de pensar e conceber as relaçóes espaço-temporais. Decorrentes destas tecnologias, Flusser identifica três épocas diferenciadas: uma pré -histórica, uma histórica e uma pós-histórica, sendo a primeira aquela da tecnologia das imagens analógicas (vinculada à magia), a segunda aquela da emergência da escrita (vinculada ao desenvolvimento das imagens em linhas: a escrita) e a terceira aquela da emergência das imagens digitais (na qual o tempo năo responde mais às condiçóes narrativas da História). Vejamos o que disso interessa para o nosso problema:

Do lado das palavras estas criam, no desenvolvimento dos seus signos gráficos, um espaço homogêneo e um tempo contínuo. A escrita aparece assim como uma linha se desenvolvendo e construindo o sentido como sucessivo, causal, narrativo, histórico: o antes e o depois, o passado e o futuro têm no presente seu ponto de divisăo. $O$ presente é resultado do passado acumulado e guarda nele o futuro por vir. A escrita produz o espaço como homogeneidade e o tempo como continuidade configurando o sentido como História.

Ter uma experiência do mundo é se colocar no ponto preciso em que passado e futuro coincidem: aqui e agora. Desse modo se cria também uma comunidade tecida a partir dos fios que lançam as palavras. Fazer parte, tomar parte da comunidade é 
pertencer à comunidade de diálogo pela qual nos é fornecida uma identidade: falamos a mesma língua (no limite a Humanidade, para além do aspecto "Babel", fala alguma língua). Assim, a análise que se debruça sobre a linguagem identifica as estruturas repetidas do homogêneo e do contínuo (nas quais uma Comunidade se dá a si mesma como sempre presente): essas estruturas organizam a ordem do discurso e asseguram as identidades dos sujeitos falantes no interior delas.

Qual é o limite da linguagem? A literatura contemporânea tem trabalhado com afinco na transposiçấo desse limite. Clarice Lispector tem mostrado as fronteiras do inexpressivo que ameaça toda palavra: o grito e o silêncio, quer dizer, a desarticulaçâo do que a linguagem tenta expressar, o limite do que a História pode narrar. A ausência da estrutura: eis o abismo das análises literárias: năo encontrar no fundo do que se lê uma estrutura comum às Línguas. A literatura se revela como a borda da Linguagem e como incapacidade da História para articular as partes do tempo: fora do que se diz, fica "o que năo conta". A literatura mostra que no limite do "comum" aparece, como um fantasma que năo cessa de nos assolar, uma incomunidade: aquilo que năo se deixa capturar nas redes nem no tecido da estrutura narrativa.

Do lado das imagens nâo há linhas retas, nem pontos, nem continuidades sequenciais: há "blocos de luz" (sejam estes blocos produtos da emergência técnica ou do devir infinito da vida) construindo fragmentos de espaço heterogêneos e de tempos descontínuos, năo causais. Desconectados entre si, esses fragmentos fornecem uma visăo ela mesma cindida em e pelo que se vê. Fragmentos que săo tirados fora de qualquer narraçăo e produzindo um sentido năo-histórico da temporalidade: no presente coexistem o passado e o futuro e as relaçōes entre eles năo sâo de estrutura mas de montagem. Trata-se de duraçăo, năo de sucessâo.

O "agora" das palavras é substituído pelo "durante" das imagens. As imagens fragmentárias produzem o sentido como memória. Uma comunidade de visíveis, nâo uma comunidade de língua. Ser parte da comunidade năo é falar, mas se dar a olhar num horizonte comum de visibilidade. E isso, segundo uma modalidade que náo responde aos critérios temporais do antes e do depois. A comunidade do visível aquela que compartilha um modo de se apropriar da Memória, segundo uma relaçăo dialética entre lembrar e esquecer. Já náo se trata de encontrar estruturas por detrás do que se diz, senăo de produzir montagens que, a cada vez, reconfiguram o valor do presente segundo essa dialética pela qual algumas coisas merecem ser lembradas e outras devem permanecer na escuridăo do esquecimento.

Qual é o limite das imagens? O cinema tem mostrado isso de duas maneiras: 1) como incapacidade das imagens de estar presentes e de nos mostrar aquilo que foi (limite das imagens para registrar as condiçóes do visível), como é o caso do cinema de Rithy Panh tentando reconstruir o passado na ausência das imagens. 2) mostrando os paradoxos da montagem: se a Memória aparece como dialética entre lembrar e esquecer, o cinema nos mostra que essa dialética náo cessa de se reconfigurar; a cada vez, emerge alguma coisa na tela que causa o desaparecimento de outra. O cinema mostra assim: a) que nem tudo se deixa apanhar pelo brilho da luz da tela que nos cega e que, talvez, o que importa seja aquilo que náo se deixa olhar e b) que aquilo que se dá ao olhar na tela está, ele mesmo, habitado pelos fantasmas que nela náo se mostram. Uma incomunidade da visâo, que nâo encontra lugar nos dispositivos da visibilidade contemporânea. 
Resumindo, cinema e literatura apresentam náo o mesmo tempo nem o mesmo espaço em duas modalidades. Mas dois tempos e dois espaços diferenciados. E, assim, dois sentidos e duas formas de compreender nossa experiência: um que fixa nossa sensibilidade aos princípios do aqui e do agora, outro que o faz devir da lógica, pela qual lembranças e esquecimentos se superpóem numa duraçăo sem fim. Um tentando recuperar o passado para legitimar o presente visando ao porvir, outro inventando o passado para confabular o presente como porvir.

Podem se articular, partindo destas diferenças alguns princípios "metodológicos" para aqueles que pretendem analisar as relaçôes entre imagens e palavras (entre cinema e literatura), como chave para a compreensăo da experiência de nosso presente: em primeiro lugar, năo procurar aproximaçôes entre a literatura e o cinema. Pelo contrário, recusar toda tentativa de encontrar semelhanças ou similitudes entre as formas literárias e as formas cinematográficas: fica claro que, se o estruturalismo é possível como ferramenta para nos confrontar com a experiência da escrita (embora se confrontando como o limite em que a literatura desfaz toda tentativa estrutural), o cinema pensa em termos de relaçôes de montagem, isto é, de "colar e pegar" fragmentos de uma realidade heterogênea como modo de fazer aparecer na tela um "visível comum"). Embora o cinema confronte essas análise com a incapacidade de fazer do olhar um princípio fundador da Comunidade Visual.

Em segundo lugar, tentar, tanto e quanto for possível, elaborar modos de análise que respondam às peculiaridades materiais assinaladas: nem fazer um "estudo cinematográfico" dos livros, nem fazer uma análise "narratológica" dos filmes e, particularmente, năo tratar o cinema como se fosse algum tipo de "linguagem". Em terceiro lugar, estabelecer as condiçóes dos problemas específicos à literatura e ao cinema consideradas suas materialidades (por exemplo, a questấo que diz respeito à noçâo de "presença" parece pertencer, em sentido estrito, às consideraçóes derivadas das imagens audiovisuais mais do que às derivadas da linguagem literária. $\mathrm{O}$ que equivale dizer: mais voltada para o problema da duraçấo dos tempos do que para a articulaçâo entre passado e futuro).

Essa questăo é central para delimitar também o tipo de análise dos filmes: năo se trata, neste caso, nem de se tomar como objeto a narraçăo (nem de eleger o seu contrário complementar: a năo narraçăo), senăo de algo que as palavras nâo poderiam reconhecer na frente do que elas năo săo. Como sustenta Deleuze (INFORMAR ANO), no cinema o nível do narrativo é decorrente da organização própria das imagens e náo o seu ponto de partida. Atingir a economia das imagens, exige renunciar a qualquer modo de aproximaçáo que provenha da experiência literária, renunciando ao "narrar" ou ao "comentar" os filmes como se fossem um romance. Aliás essa exigência acompanha o cinema desde o seu nascimento: se afastar do que năo é cinema (nem pintura, nem teatro, nem literatura) é o esforço comum de artistas como Gance ou Epstein , tanto como de teóricos como Munsterberg ou Canudo - só por citar alguns deles, e isso para além do que diz respeito ao caráter "impuro" do cinema.

Em quarto lugar, manter-se, tanto e quanto é possível, no movimento desse intervalo inicial, dessa separaçăo, dessa "năo relaçăo" entre olhar e falar entre a literatura e o cinema. E, desse modo, náo aproximar as experiências das imagens e das palavras, senáo tentar conservar a tensăo do seu afastamento. O território de nosso presente 
pode se pensar como o movimento que se abre entre literatura e cinema, nesse movimento que, irredutivelmente, afasta uma do outro.

Há um desafio sempre posto quando se pretende adaptar um texto a uma imagem, uma impossibilidade para se reduzir uma imagem a um texto constituindo uma cisáo que náo cessamos de enfrentar. Aparece, desse modo, uma caraterística da experiência de nosso presente que resulta, na minha perspectiva, marcante. Essa distância entre palavras e imagens é, ela mesma, o signo da năo conciliaçăo dos tempos e de nós mesmos no interior dos tempos. literatura e cinema mostram o caráter inconciliável do presente com ele mesmo e com os tempos que nele colidem. Temos de nos confrontar a nossa própria "inconciliabilidade": aquela pela qual diante de cada gesto, frente a cada acontecimento, se abre para nós uma legibilidade e uma visibilidade que nâo têm ponto em comum entre elas. Ao mesmo tempo nos desdobramos em um mundo de palavra e imagens manifestando uma "nâo-relaçăo". Ou uma relaçăo feita de duas heterogeneidades que năo tem entre sim ponto comum.

\section{Em que acreditar?}

Tentei apresentar a diferença aberta entre palavras e imagens como duas modalidades do tempo (História e Memória) se confrontando em nosso presente (duas modalidades do tempo que fazem do presente o resultado desse confronto, que estabelecem no interior do presente uma cisăo). Decorrente da materialidade da escrita, a História produz o tempo como continuidade causal e sucessiva articulando os muitos pontos de uma linha. E, decorrente da materialidade das imagens, a Memória o produz uma relaçâo entre fragmentos descontínuos que se organizam segundo uma lógica que reconfigura, a cada vez, as posiçôes relativas do passado, do presente e do futuro.

Narraçáo e montagem resultam das operaçōes específicas no interior de cada uma dessas produçóes. Por isso mesmo parece desnecessário tentar comparar as qualidades pelas quais essas operaçóes se apropriariam do tempo (de fato toda a questâo é que eles năo disputam o mesmo tempo, senáo como afastamento): a disputa entre os limites do narrativo e do náo-narrativo, articulando o percurso entre uma origem e um fim, apenas tem sentido no interior da experiência literária. No interior da experiência cinematográfica a questáo estará marcada pelas possibilidades das imagens de tornar visível e de fixar, numa identidade visual, a condiçâo aberta da Memória que reconfigura o presente segundo as apropriaçôes do passado.

O problema se apresenta, desse modo, como um índice do acontecimento pelo qual o tempo está "fora dos seus eixos": liberado do movimento que media, ele mesmo perde agora sua medida, ele mesmo é sem medida, sendo a cisâo que nos atravessa (essa que lançou Édipo ao deserto, segundo a interpretaçâo de Hölderlin (2008): na perspetiva do poeta alemâo, a tragédia do homem moderno começa quando este e os deuses afastamse um do outro; Édipo náo pode retornar à pátria e perambula num exílio cujo cume está fixado pela morte. O tempo em que os deuses asseguravam o destino e a vida se perdeu e agora o Homem tem que inventar-se a si mesmo diante de um tempo sem final).

Porém, se abre também para nós, nesse movimento que afasta nossas bordas, outro problema: a perda dos eixos do tempo é também a perda do sentido da justiça (como 
mostra Derrida (1993), a expressâo "The time is out of joint" foi traduzida por Gide como "os tempos são desonestos"). Num tempo que năo tem eixos, num tempo no qual năo há Oriente (tempos desorientados) e onde a sentença dos deuses năo organiza o destino, num tempo onde a vida parece sem justificativa, o problema será como saber o que é justo ou injusto. Em que podemos acreditar, a que dar crédito, em que ter confiança, como consentir quando o que se diz e que se olha năo concordam entre eles? ${ }^{3}$ Sem a unidade do tempo é ainda possível julgar?

Porém, isto poderia ser apresentado partindo de outra perspectiva: História e Memória se afastam também segundo suas duas "epistemologias": uma que diz respeito à verdade dos fatos; outras que diz respeito ao sentido dos acontecimentos. Uma que diz respeito à possibilidade de julgar (no interior da linguagem se articulam as partes de um relato e se estabelecem as condiçōes da verificaçăo dos fatos: a linguagem diz: “É, nâo é."). A outra que diz respeito às condiçôes em que se afirma a crença (no interior das imagens: elas dâo a olhar, elas săo testemunham da referência, pois dizem "isso foi"). Na primeira, os fatos săo estabelecidos segundo a unidade do aqui e do agora próprios do tempo histórico que lhes fornece identidade. Na segunda, os acontecimentos náo se situam numa dimensăo espaço-temporal contínua e nâo obedecem as relaçôes estabelecidas pelo princípio de causalidade, porém revelam uma dimensâo que vai para além da distinçáo do verdadeiro e do falso: na Memória, trata-se do que faz sentido, do que permite a vida se tornar vivível). Do fato ao acontecimento, das condiçôes causais da verdade ao sentido inesgotável e sem causas o presente (nosso presente) oscila no paradoxo político pela qual os tempos se recusam.

Desse modo, a distância entre palavras e imagens náo determina apenas uma disputa pela forma do tempo, mas deflagra também, nesse mesmo vazio, a questăo política da vida em comum. A questăo da experiência do que somos, do que podemos dizer e fazer no interior da distância que tem se aberto entre as palavras e as imagens. História e Memória năo apenas tentam se apropriar da unidade do tempo, senâo também do modo de pensar uma comunidade. Do presente no qual a comunidade é pensada. Os tecidos das palavras e os fragmentos do visível apresentam modos diferentes de criar uma vida em comum. Estamos no meio desses tecidos mas, também e "ao mesmo tempo", no meio desses fragmentos. Estamos entre eles, tentando reconstruir o fio perdido nas palavras, tentando costurar o elo perdido nas imagens. Sem esperança de totalizar o existente seja como universalidade de língua, seja como identidade dos olhos. literatura e cinema percorreram, nas beiras dos tempos a que pertencemos, os limites pelos quais se apresenta a insuficiência das totalizaçôes políticas: nem tudo será enunciável, nem tudo será visível. Trata-se do movimento pelo qual, palavras e imagens, atingido as fronteiras dos tempos que elas produzem, abrem a fuga e realizam a experiência da incomunidade no movimento de uma dispersăo que elas năo retêm. Essa incomunidade, essa cisăo do inconciliável é a marca pela qual palavras e imagens tornam perceptível a contradiçâo disto que somos.

Sâo os sentidos possíveis dos verbos "crer" e "acreditar". Como se pode ver, todas as entradas chamam a atençăo para a questăo do tempo: todas supóem uma relaçấo com um porvir que assegura a crença. 


\section{Referências Bibliográficas}

CALVINO, I. As cidades invisíveis. Săo Paulo: Companhia das Letras, 1990.

DECERTEAU, M. História e psicanálise: entre ciência e ficçâo. Belo Horizonte: Autêntica, 2011.

DELEUZE, G. Logique du sens. Paris: Minuit, 1969.

; GUATTARI F. O que é a filosofia? Săo Paulo: 34, 2010.

DERRIDA, J. Spectres de Marx. Paris: Galilée, 1993.

FLUSSER, V. Filosofia da caixa preta. Sáo Paulo: Huicitec, 1985.

FOUCAULT, M. As palavras e as coisas. Săo Paulo: Martin Fontes, 1891.

. Dits et Ecrits. France: Gallimard, 1994. v. 1-4.

A ordem do discurso. Săo Paulo: Loyola, 1996.

A arqueologia do saber. Rio de Janeiro: Forense Universitária, 2000.

.0 uso dos prazeres. In.:

. (Org.). História da sexualidade. Traduçâo: Maria Thereza da Costa Albuquerque; Revisâo técnica: José Augusto Guilhon Albuquerque. Rio de Janeiro: Graal, 2003.

HÖLDERLIN, F. Observaçôes sobre Édipo. Observaçôes sobre Antígona. Rio de Janeiro: Zahar, 2008. 